\title{
APPLYING AHP TO THE PRIORITIZATION OF MARITIME BOOKING CONFIRMATION
}

\author{
Denise Lindstrom Bandeira** \\ Management School \\ Universidade Federal do Rio Grande do Sul \\ Porto Alegre, RS, Brazil \\ E-mail: dlbandeira@ea.ufrgs.br \\ João Luiz Becker \\ Management School \\ Universidade Federal do Rio Grande do Sul \\ Porto Alegre, RS, Brazil \\ E-mail: jlbecker@ea.ufrgs.br \\ Amanda Kruse Rocha \\ Management School \\ Universidade Federal do Rio Grande do Sul \\ Porto Alegre, RS, Brazil \\ E-mail: akrocha@terra.com.br
}

\begin{abstract}
This paper presents an application of the Analytic Hierarchic Process (AHP) technique in helping a decision making process of a group of executives of a ship agency operating in southern Brazil. The decision comprised the prioritization of maritime booking confirmation for shipments of export cargoes at a particular time, in a situation of scarcity - a lack of empty containers or reduced allocation on available vessels. The method proved to be appropriate to expand the minds of the decision makers giving them the opportunity to incorporate other factors beyond the purely financial view in the decision making process, such as managerial and organizational factors. The factors specification, as well as their hierarchical structure and relative weights, was subject of discussion by the group of executives, finally reaching a consensus. Four alternative solutions were evaluated, lastly getting the best collective decision. The validation of the process by the group of executives included an assessment of the quality of the decision making progress. The main difficulties reported by the executives were related to the comparison between the alternatives. While the pairwise comparisons of the criteria haven't showed major problems of consistency, the comparisons between the alternatives presented initial inconsistencies for the executives. Such inconsistencies were removed during the bargaining process and accommodation of participants' opinions. The executives involved were unanimous in stating their satisfaction with the results obtained using the technique.
\end{abstract}

Keywords: group decision making, shipping allocation, decision support systems, shipping agency

\section{Introduction}

Marine transport is characterized as taking place in oceans and seas, by means of large vessels, carrying various types of cargo between ports within the same country or in different countries. It is

\footnotetext{
${ }^{*}$ Corresponding author

* The authors would like to thank CNPq and CAPES, two Brazilian governmental agencies, for supporting the research on which this work was based.
} 
carried out by ship owners, legal entities established and registered in a determined country with the purpose of providing local or international sea transport, through the operation of vessels, exploiting determined routes. When transporting cargoes of any kind from one port to another, the ship owner is held responsible for the cargo being transported. However, contact between the traders and the ship owners does not usually take place directly, but is mediated by shipping agents. The shipping agency is a firm that represents the ship owner in a certain region or even in a particular port, acting as his legal representative. It serves as intermediary between the ship owner and the trader, whether it is an importer or exporter, controlling the loading and discharge operations and allocating cargo for the space available on the vessels. The shipping agency also represents the ship owner before the port and governmental authorities.

Over the years, in relation to the international movement of cargo, Brazil has predominantly been an exporter, as shown in Figure 1.

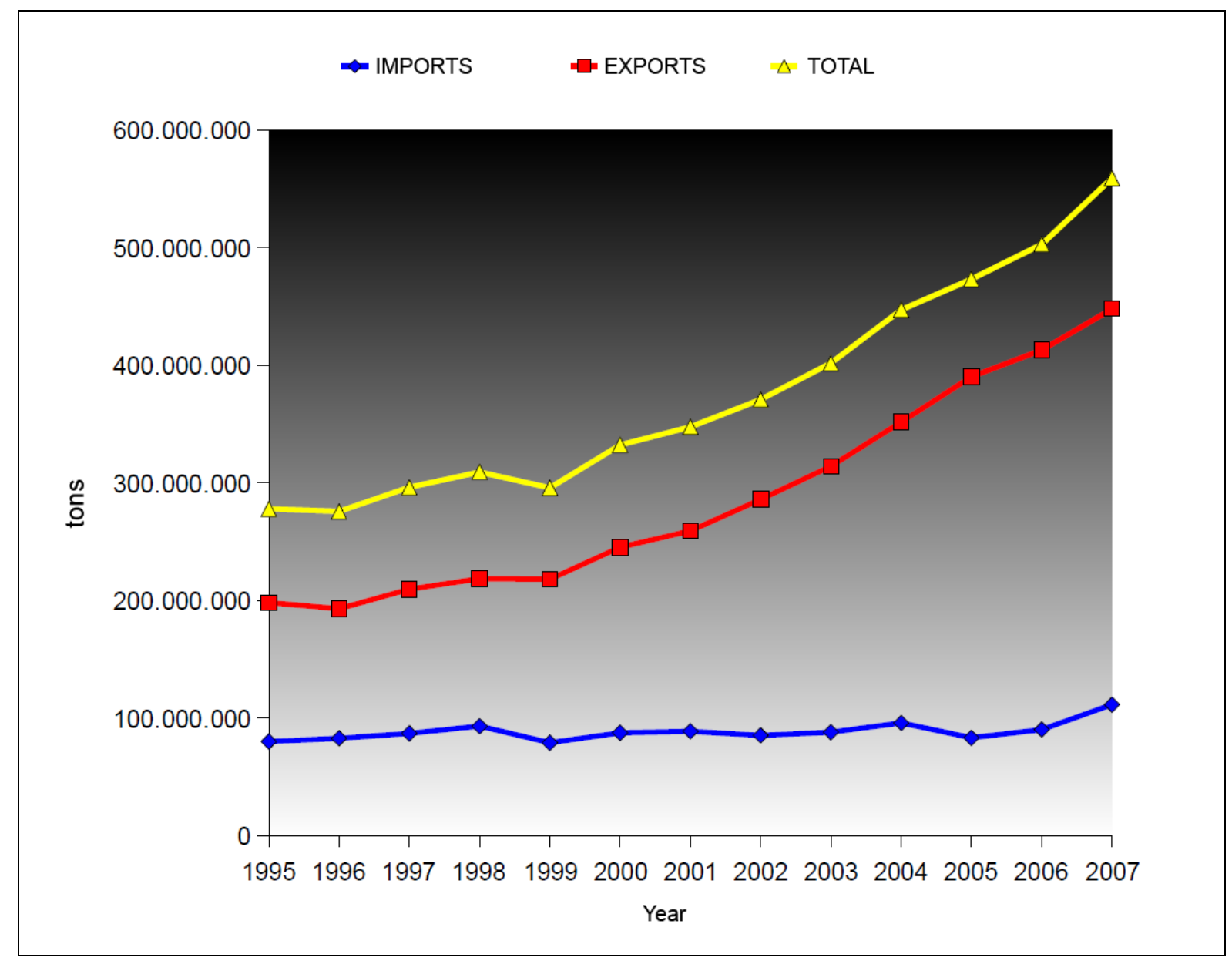

Source: ANTAQ (2009).

Figure 1. Evolution of the movement of cargo (foreign trade) in Brazil, by direction (1995-2007).

This reflects the economic conditions and the position of Brazil in comparison with other nations in the world. According to the World Trade Organization, in 2007 Brazil ranked $24^{\text {th }}$ among export countries and $28^{\text {th }}$ among import countries (WTO, 2009). The exporting goods are predominantly mineral and agricultural commodities (50\%) and manufactured goods (47.2\%). The profile illustrated in

Figure 1 similarly emerges when one analyses the volume of foreign trade using containers. According to the Brazilian National Waterways Transport Agency, international shipping in Brazil 
involved the movement of 3,475,693 twenty and forty-feet containers in 2007 (ANTAQ, 2009). Table 1 shows the container movement in Brazil and its southernmost sea port, in the City of Rio Grande, in 2007.

Table 1

Movement of 20' and 40' containers in the privately organized ports and terminals, in international shipping, by direction - 2007.

\begin{tabular}{|c|c|c|c|c|c|c|c|c|}
\hline \multirow{3}{*}{ Port } & \multicolumn{4}{|c|}{ Inbound } & \multicolumn{4}{|c|}{ Outbound } \\
\hline & \multicolumn{2}{|c|}{ 20' } & \multicolumn{2}{|c|}{$40^{\prime}$} & \multicolumn{2}{|c|}{20 ' } & \multicolumn{2}{|c|}{$40^{\prime}$} \\
\hline & Full & Empty & Full & Empty & Full & Empty & Full & Empty \\
\hline Rio Grande & 22,661 & 25,668 & 26,361 & 83,263 & 44,180 & 3,741 & 105,118 & 5,190 \\
\hline Brazil & 464,514 & 297,024 & 535,868 & 435,761 & 693,113 & 58,568 & 879,544 & 111,301 \\
\hline
\end{tabular}

Source: ANTAQ (2009).

As can be seen, the movement of goods outbound (around 1.5 million full containers in 2007) is much greater than the movement of goods inbound (around one million full containers in 2007). While this imbalance does not cause great concern if one is transporting goods in bulk carriers, it becomes critical when dealing with the movement of containers. Empty containers will need to be transported to fulfill the gap (around 0.5 million empty containers in 2007), generating additional costs, without the freight compensation for the ship owners.

For the shipping agent, the limited capacity of the vessels and the relative scarcity of empty containers give rise to the problem of prioritization when attending to requests from clients, within a given time frame.

The objective of this article is to present a method of prioritization of confirming bookings for the shipment of cargoes for export at a specific moment in time, in a situation of scarcity - a lack of empty containers or space on the available vessels - by applying the Analytic Hierarchy Process (AHP) technique. The purpose is to demonstrate that by applying the technique it is possible to analyze criteria beyond those of a purely financial nature, taking into consideration other managerial and organizational factors that can improve the quality of the decision. The use of the AHP technique has allowed managers to create scenarios for existing situations, which may help in the decision making process. The aim in applying this technique in a shipping agency is to select criteria that strategically contribute towards the assessment of diverse demands for space, so facilitating enhanced prioritization. For the sake of convenience, the study is limited to the Port of Rio Grande, in the State of Rio Grande do Sul, Brazil, especially regarding the availability of data for analysis and the possibility of interviewing the managers responsible for making decisions. Later, it is hoped that the method developed can be extended to other similar situations.

The paper is organized as follows: section 2 gives the background to the study and the problem situation; section 3 describes the technique and the solution used, with the method being introduced in section 4; while in section 5, the model is further developed; in section 6 the results obtained are analyzed; and in section 7 there are some final remarks.

\section{Background to the study}

\subsection{Characterization of the company}

The shipping agency in the study has been established in Brazil since 1837. It is the agency with the most extensive national coverage along the Brazilian coast operating in approximately 45 ports from the Port of Rio Grande in the State of Rio Grande do Sul to the Port of Manaus in the State of Amazon. It accounts for around 13\% of the total container movement in Brazil, specializing in liner and tramp shipping (vessels operating on regular lines and non-regular lines, respectively). In 2006 it 
dealt with 6,630 vessels and had net revenues of US\$17.8 million from shipping agency services. Its base of more than 7,000 clients includes firms from diverse sectors on all five continents.

The paper focuses on the work of the agency in relation to regular routes from the Port of Rio Grande, offered by an international ship owner that operates a diversified fleet of vessels for containers, cars, bulk carriers, oil, gas, general cargo and passengers, totaling more than 700 ships.

The services offered by the ship owner from the Port of Rio Grande involve two lines: East Coast South America - Africa - Asia (CSW), in partnership with other ship owners, and the American Coast Express (ACX), renting slots in third party vessels. The export route of the CSW service is Buenos Aires - Montevideo - Paranagua - Sao Francisco Do Sul - Santos - Rio de Janeiro - Cape Town - Port Elizabeth - Singapore - Hong Kong - Kobe - Yokohama - Nagoya - Busan - Shangai, with a weekly feeder service between Buenos Aires - Montevideo - Rio Grande (Figure 2). The CSW line operates with a total of 11 full-container vessels with a capacity of 2,800 TEUs.

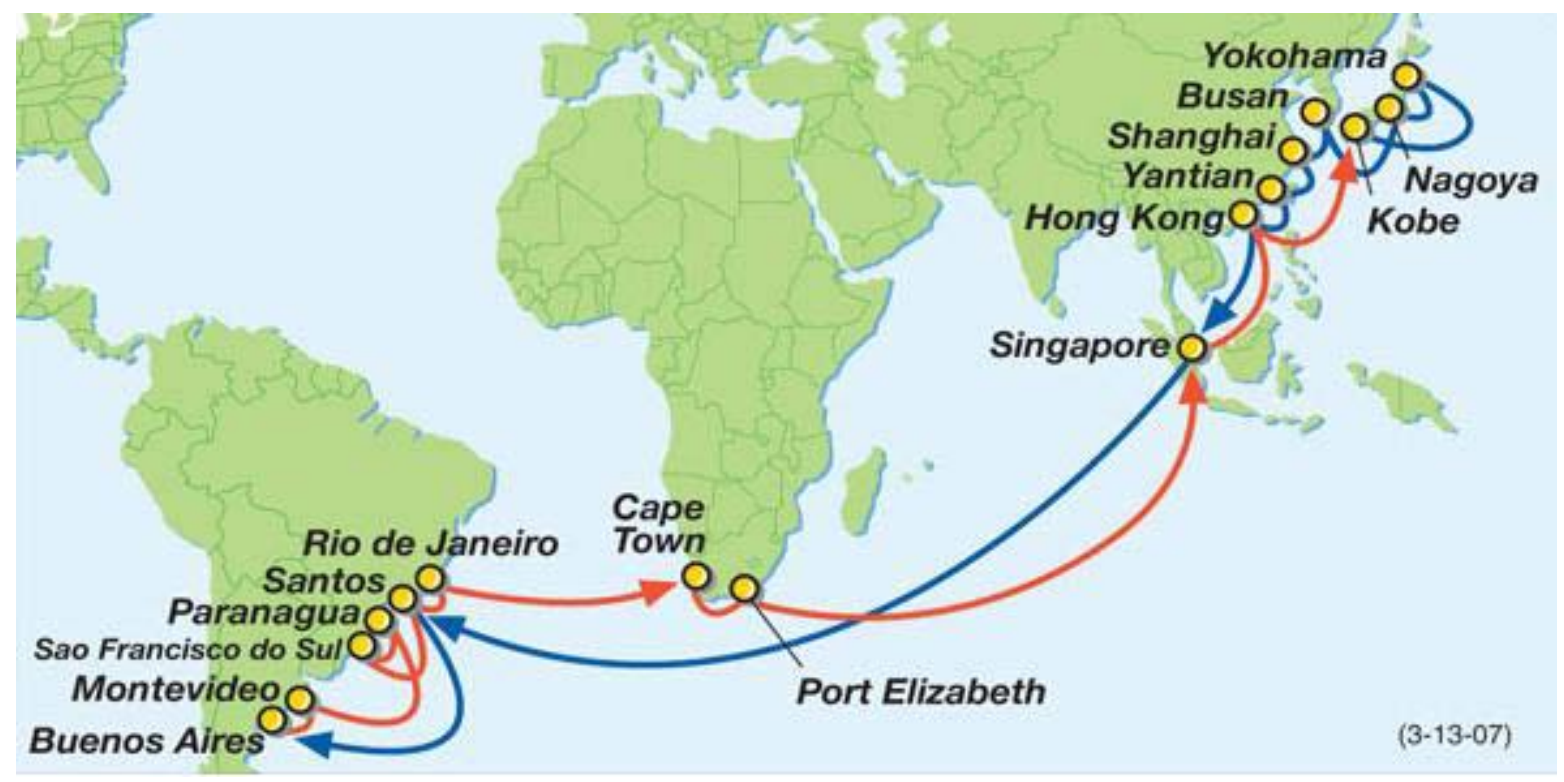

Figure 2. CSW service route.

The transit times from the Port of Rio Grande to the direct destinations of the CSW service are shown in Table 2: 
Table 2

Transit time of the CSW service.

\begin{tabular}{|l|c|}
\hline \multicolumn{2}{|c|}{ Transit times from the port of Rio Grande to other ports served by CSW } \\
\hline City & Days \\
\hline Cape Town (South Africa) & 21 \\
\hline Port Elizabeth (South Africa) & 24 \\
\hline Singapore (Singapore) & 37 \\
\hline Hong Kong (Hong Kong) & 41 \\
\hline Kobe (Japan) & 46 \\
\hline Yokohama (Japan) & 47 \\
\hline Nagoya (Japan) & 48 \\
\hline Busan (Korea) & 50 \\
\hline Shanghai (China) & 52 \\
\hline Yantian (China) & 54 \\
\hline
\end{tabular}

The coverage of the ACX line is: Buenos Aires - Rio Grande - Sao Francisco do Sul - Santos Salvador - Norfolk - Philadelphia - New York - Baltimore - Buenos Aires (Figure 3).

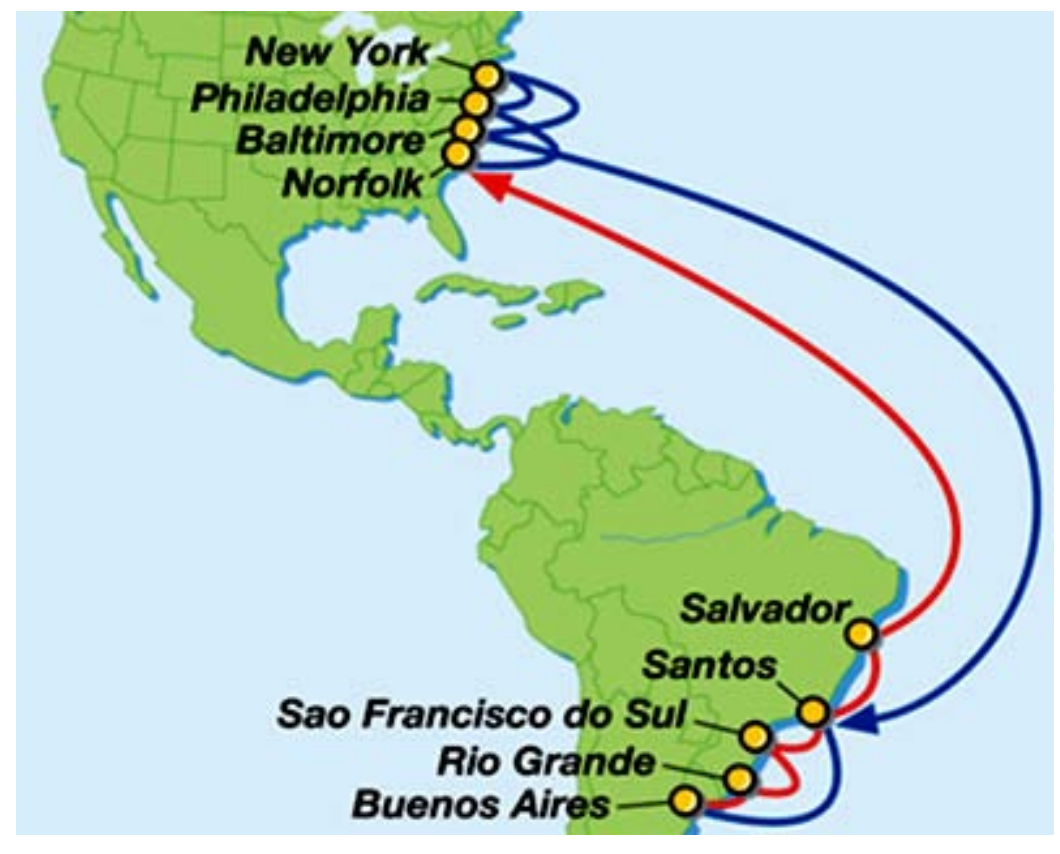

Figure 3. ACX service route.

The transit times from the Port of Rio Grande to the direct destinations of the ACX service are shown in Table 3: 
Table 3

Transit time of the ACX service.

\begin{tabular}{|l|c|}
\hline \multicolumn{2}{|c|}{ Transit time from the port of Rio Grande to other ports served by ACX } \\
\hline City & Days \\
\hline Norfolk & 18 \\
\hline Philadelphia & 20 \\
\hline New York & 21 \\
\hline Baltimore & 24 \\
\hline
\end{tabular}

\subsection{Problem situation}

As previously indicated, the Brazilian trade balance, particularly that of the State of Rio Grande do Sul, is markedly unbalanced in favor of exports. As a result, the cargo movement market in the port of Rio Grande is characterized by a relative scarcity of containers and space on container vessels. Hence, one of the recurring problems faced by the shipping agency is the prioritization of their clients' cargo at the scheduled ports of call. Cargoes held over at a certain port of call, due to scarcity of space, are scheduled for the following stopover, producing dissatisfaction among the clients, and so increasing the risk of the agency losing them to the competition. The problem is customarily solved informally, sometimes the most profitable allocation is chosen, and sometimes the allocation goes to the most loyal client, thus dropping managers' confidence because they feel the rules and procedures might be somehow inconsistent.

The ship owner's allocation in the port of Rio Grande is smaller than the demand from the clients that use the port for their shipments. In the CSW line, the allocation is limited because the port is attended by transshipment. The space is limited, therefore, due to the additional cost of moving the cargo from Rio Grande to Montevideo by a feeder service. In the ACX line, the space is limited by the renting space contract on the vessels of a third-party ship owner.

In addition, frequently there are no empty 40 feet containers available in Rio Grande due to the difficulty of repositioning empty units. The units that arrive with imports at Rio Grande are, for the most part, 20 feet in length.

\section{Analytic Hierarchy Process (AHP)}

The Analytic Hierarchy Process is a technique for analyzing complex decision problems involving multiple criteria, developed by Thomas L. Saaty in the mid 1970s (Golden, Wasil, and Harker, 1989).

AHP is based on the human mind relative easiness to establish comparisons between two objects (pairwise comparisons). A classification of objects within a group can then be easily obtained appropriately combining all pairwise comparison of objects in the group. The multiplicity of paired comparisons might generate inconsistencies, which will be interpreted as errors of the cognitive process. As usual, errors are generally averaged out, in this case using the eigenvector method as proposed by Saaty.

The simplicity of the process, which allows assessment of qualitative and quantitative as well as tangible and intangible factors, combined with a rigorous mathematical treatment confer great flexibility to the technique. Coupling it with techniques aiming at getting consensus of judgments from different individuals, with different points of view or experience, one gets a powerful group decision support tool. Today, AHP is one of the most widely known and used tool to deal with complex decisions.

Applying the technique is divided into two steps: structuring and assessment. Structuring refers to the development of a hierarchical structure that models the relations among the overall goal of the 
decision, criteria that translate the goal, subcriteria, and decision alternatives (see Figure 4). Assessment refers to the value judgments that should be established between different alternatives given each criterion or subcriterion, if there is any, between the subcriteria given each criterion from which it is part of, and between different criteria given the goal.

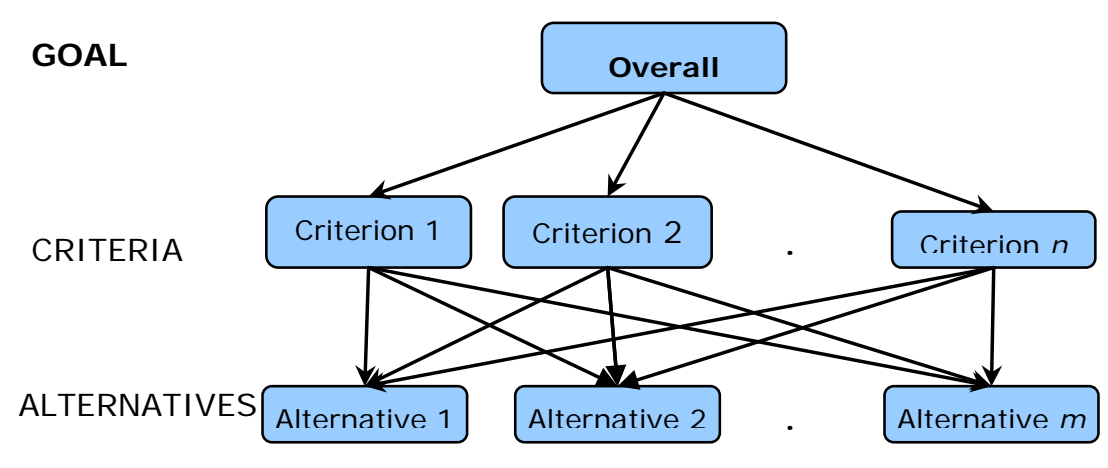

Figure 4. Hierarchical model used in the AHP technique.

As the assessment is constrained by the hierarchical model, it ought to be well established among the decision makers prior to starting the second step. Specifically, the decision makers should ensure that the hierarchical structure is complete (all the important alternatives and criteria for the decision are duly represented in the hierarchy) and nonredundant (there are no redundancies among criteria or alternatives). Additionally, the technique requires that the criteria are independent of each other.

Saaty (1980) suggests that the assessment step proceeds through pairwise judgments organizing the objects under scrutiny (criteria, subcriteria, alternatives) in squared matrixes, whose elements indicate the importance of an object (line) compared to another (column). The author also suggests the use of a nine points ratio scale representing the importance or relative preference, as shown in Table 4.

Table 4

9-point comparative scale.

\begin{tabular}{|c|l|}
\hline Numerical values & Definition \\
\hline 1 & Equally important or preferred \\
\hline 3 & Slightly more important or preferred \\
\hline 5 & Strongly more important or preferred \\
\hline 7 & Very strongly more important or preferred \\
\hline 9 & Extremely more important or preferred \\
\hline $2,4,6$ e 8 & Intermediate values to reflect compromise \\
\hline
\end{tabular}

Once the information corresponding to the judgments has been organized within matrixes, the next step is to produce a composite measure of the importance or preference of the objects, so furnishing their relative priority. Saaty proposes the use of normalized eigenvectors associated to the largest eigenvalue of the matrix. The eigenvectors represent the average of all possible ways of comparing the objects two by two. A comparison between the value of the highest eigenvalue and the order of the matrix produces an interesting inconsistency measure (consistency index CI) of the judgments represented in the matrix. A comparison of this with measures of consistency of matrixes of the same order generated randomly produces a measure called consistency ratio (CR), used to gauge the general quality of the judgment process. CR values lower or equal to 0.1 are considered acceptable. Values over 0.1 indicate that the decision makers should attempt to reduce the judgment inconsistencies, perhaps reassessing their initial judgments. 
Vaidya and Kumar (2006) and Ho (2008) offer comprehensives literature reviews of international applications of the AHP technique. In Brazil, several papers (SCIELO, 2009) and more than a hundred PhD dissertations and MS thesis have been developed using AHP (CAPES 2009).

\section{Method}

This study follows the well known OR methodology framework (Ackoff and Sasieni, 1968). A model aiming to help the decision to prioritize cargo booking confirmations by a shipping agency was developed. The classic steps of an OR study were used: problem formulation (how to prioritize shipment bookings beyond the view of the strict financial analysis); model building (see section 5.1); model solution (AHP technique, using a computer spreadsheet, see sections 5.2 to 5.4); model evaluation and assessment of the solution (face validation with the executives from the firm, see section 6); and final assessment (see section 7).

\section{Development of the model}

This section describes the use of the AHP technique to develop a model of multicriteria assessment for prioritizing maritime booking confirmations at a specific moment in time.

\subsection{Construction of the hierarchical model}

Figure 5 shows the hierarchical tree developed in the study.

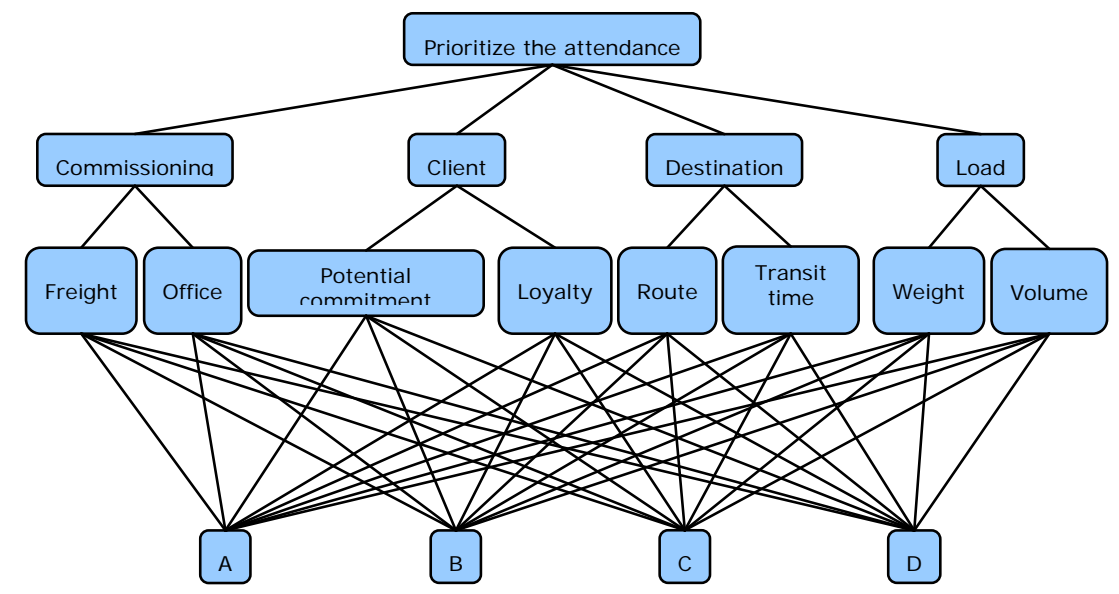

Figure 5. Hierarchical structure for the maritime booking problem.

The goal at the first level is defined by the question "how to prioritize the requests of export demand from the clients of a shipping agency?". The criteria and subcriteria in the second and third levels, respectively, were obtained interactively, in successive meetings with the sales team of the Porto Alegre branch of the company, formed by four employees and the sales manager.

Based on the company's strategic plan and sales goals, the group was asked to reflect on which criteria should be considered significant when differentiating among the various requests from the clients, when confirming bookings. Four criteria emerged from the process: commissioning, client, destination, and load. Commissioning refers to details of the cargo itself, broken down into two subcriteria: monetary value of the freight, and relative importance of the office responsible for confirming the booking. Client refers to aspects valued by the company in its relationship with the clients, such as potential commitment (future) and loyalty (past). Destination refers to aspects linked to the cargo movement itself, and is broken down into two subcriteria: competitive positioning of the 
company relative to its competitors on the route chosen by the client, and the transit time. Load refers to physical characteristics of the shipment, and is broken down into two subcriteria: weight and volume.

The operational definitions of the subcriteria (third level) are explained below.

- Freight - refers to the monetary value of the sea freight, expressed in US dollars (USD) established by the ship owner and accepted by the client.

- Office - is the office responsible for the negotiation with the client and effective confirmation of the port of call, since the commission received from the ship owner will be shared between those involved (representative of the port of embarkation and the regional office closest to the client).

- Potential commitment - is considered the status of the client in the market, his overall influence power and partnerships.

- Loyalty - refers to the support given by the client to the agency in the recent past.

- Route - is considered the route of the cargo until its final destination, analyzing the competitive position of the company regarding its competitors, such as exclusivity or interest in the route. The shipments can be direct or serviced via transshipment, considering the current situation of each port and the transshipment services to the final destinations.

- Transit time - refers to the estimated transit time (in days) from the port of embarkation until discharge of the cargo unit at its final destination.

- Weight - refers to the weight (tons) of the load.

- Volume - refers to the overall volume involved per unit of time (containers/month).

The last level, representing the decision alternatives, refers to clients' demands for the company's services, at a given time. The case of a specific week is described below. In this week, there are two regular clients and two potential clients that had called the agency requesting quotations for sea freight and bookings. The booking dates are confirmed as soon as the availability of space and equipment for the requested week is released.

A brief description of each alternative follows.

Alternative A: Client "A" is a cargo agent specialized in the leather sector that has been in the market since 1989, and is a regular client of the shipping agency. He holds an outstanding position in the field and has agents in several countries. The request results from a quotation given to it by the shipping agency to ship approximately six tons of leather, in a 40 feet container, from Rio Grande to Cape Town, South Africa. The total volume contracted between exporter and importer is one container per month, within the next year. The freight value is US\$2,500 per container, plus fuel, storage, and release fees. The additional fees will not be considered in this study, though. Currently the company represents the only ship owner offering direct sailings to Cape Town, and space on the vessels reserved for Africa is in short supply due to the high demand.

Alternative B: Client "B" is a manufacturer from upstate Sao Paulo that mainly operates in the internal market, and has no contracts signed for future shipments. It came to the company as a result of a new account developed by the Sao Paulo branch. Therefore, if the shipment is made, the commission will be shared between the Porto Alegre and Sao Paulo branches. The request is for a container of tires, weighting approximately 26 tons. The freight value is US\$2,800 for the shipment 
from Rio Grande to Shiimuzu, in Japan, via Singapore, and the estimated transit time is 42 days. Cargoes bound for Japan are encouraged by the ship owner, since empty units are quickly reallocated in other lines belonging to the ship owner, despite the long transit time.

Alternative C: Company "C" began its customs and logistics consulting activities in 1984, and has since expanded its business allover Brazil. Despite not having confirmed shipments with the ship owners represented by the shipping agency, this client has a good relationship with the agency. The freight value was negotiated by the importer with the ship owner in the US at US $\$ 1,900$, and is part of a world service contract, which includes shipment of one container per week, on average. The present booking refers to a container with furniture, weighing approximately 20 tons, due to sail from Rio Grande to Philadelphia, US.

Alternative D: This cargo agent recently opened an office in Porto Alegre and, despite not having a large share of the market in the State of Rio Grande do Sul, it is forming a good professional team to sign partnerships with traditional exporters from the South. Client "D" requested a quotation from the shipping agency for the shipment of 14 tons of tobacco from Rio Grande to Danville, Kentucky, US. The service to be supplied by the ship owner is to discharge the container in Norfolk and truck it to the importer. The total estimated transit time is 32 days. The freight value is US\$2,300 per container.

\subsection{Comparison matrixes}

Using the hierarchical structure (Figure 4), pairwise comparisons between the objects from each hierarchical level in relation to each object in the hierarchical level immediately above were made. Given $n$ objects in a determined hierarchical level, $n(n-1) / 2$ judgments will be needed with respect to each object of hierarchical level immediately above, generating a matrix of preferences for each of these objects. The process begins with the lowest level in the structure (alternatives' level), followed by the level immediately above (in this case, the subcriteria' level), continuing by the level immediately above that (in this case, the criteria' level), successively, until the highest level is reached, corresponding to the goal of the analysis.

In order to complete the various comparison matrixes, a meeting was arranged with the sales team attempting to get a consensus and to validate the attributed values. Microsoft Excel ${ }^{\circledR}$ was used to facilitate communication among the participants and duly record the results. The pairwise comparisons of the alternatives with regard to the subcriteria are presented in tables 5 to 12 .

Table 5

Alternatives comparison with respect to freight.

\begin{tabular}{|c|cccc|c|}
\hline & A & B & C & D & Relative Priority \\
\hline A & 1 & $1 / 3$ & 5 & 2 & 0.233 \\
B & 3 & 1 & 8 & 5 & 0.579 \\
C & $1 / 5$ & $1 / 8$ & 1 & $1 / 4$ & 0.050 \\
D & $1 / 2$ & $1 / 5$ & 4 & 1 & 0.139 \\
\hline & & & & CR $=\mathbf{0 . 0 3 5}$ \\
\hline
\end{tabular}

Table 6

Alternatives comparison with respect to office.

\begin{tabular}{|c|cccc|c|}
\hline & A & B & C & D & Relative Priority \\
\hline A & 1 & $1 / 3$ & 5 & 2 & 0.233 \\
B & 3 & 1 & 8 & 5 & 0.579 \\
C & $1 / 5$ & $1 / 8$ & 1 & $1 / 4$ & 0.050 \\
D & $1 / 2$ & $1 / 5$ & 4 & 1 & 0.139 \\
\hline & & & & & CR $=\mathbf{0 . 0 3 5}$ \\
\hline
\end{tabular}


Table 7

Alternatives comparison with respect to potential commitment.

\begin{tabular}{|c|cccc|c|}
\hline & A & B & C & D & Relative Priority \\
\hline A & 1 & 9 & 3 & 5 & 0.559 \\
B & $1 / 9$ & 1 & $1 / 8$ & $1 / 4$ & 0.040 \\
C & $1 / 3$ & 8 & 1 & 4 & 0.294 \\
D & $1 / 5$ & 4 & $1 / 4$ & 1 & 0.108 \\
\hline & & & & CR $=\mathbf{0 . 0 6 7}$ \\
\hline
\end{tabular}

Table 8

Alternatives comparison with respect to loyalty.

\begin{tabular}{|c|cccc|c|}
\hline & A & B & C & D & Relative Priority \\
\hline A & 1 & 9 & 5 & 8 & 0.655 \\
B & $1 / 9$ & 1 & $1 / 6$ & $1 / 2$ & 0.045 \\
C & $1 / 5$ & 6 & 1 & 5 & 0.231 \\
D & $1 / 8$ & 2 & $1 / 5$ & 1 & 0.068 \\
\hline & & & & & CR $=\mathbf{0 . 0 8 0}$ \\
\hline
\end{tabular}

Table 9

Alternatives comparison with respect to route.

\begin{tabular}{|l|cccc|c|}
\hline & A & B & C & D & Relative Priority \\
\hline A & 1 & $1 / 5$ & $1 / 8$ & $1 / 7$ & 0.041 \\
B & 5 & 1 & $1 / 5$ & $1 / 4$ & 0.119 \\
C & 8 & 5 & 1 & 3 & 0.550 \\
D & 7 & 4 & $1 / 3$ & 1 & 0.290 \\
\hline & & & & CR $=\mathbf{0 . 0 9 7}$ \\
\hline
\end{tabular}

Table 10

Alternatives comparison with respect to transit time.

\begin{tabular}{|c|cccc|c|}
\hline & A & B & C & D & Relative Priority \\
\hline A & 1 & 7 & $1 / 2$ & 4 & 0.326 \\
B & $1 / 7$ & 1 & $1 / 8$ & $1 / 6$ & 0.040 \\
C & 2 & 8 & 1 & 5 & 0.503 \\
D & $1 / 4$ & 6 & $1 / 5$ & 1 & 0.131 \\
\hline & & & & & CR $=\mathbf{0 . 0 9 0}$ \\
\hline
\end{tabular}

Table 11

Alternatives comparison with respect to weight.

\begin{tabular}{|c|cccc|c|}
\hline & A & B & C & D & Relative Priority \\
\hline A & 1 & 7 & 5 & 3 & 0.551 \\
B & $1 / 7$ & 1 & $1 / 4$ & $1 / 5$ & 0.051 \\
C & $1 / 5$ & 4 & 1 & $1 / 4$ & 0.118 \\
D & $1 / 3$ & 5 & 4 & 1 & 0.281 \\
\hline & & & & & CR $=\mathbf{0 . 0 9 1}$ \\
\hline
\end{tabular}


Table 12

Alternatives comparison with respect to volume.

\begin{tabular}{|c|cccc|c|}
\hline & A & B & C & D & Relative Priority \\
\hline A & 1 & 9 & $1 / 4$ & 9 & 0.296 \\
B & $1 / 9$ & 1 & $1 / 9$ & 1 & 0.045 \\
C & 4 & 9 & 1 & 9 & 0.614 \\
D & $1 / 9$ & 1 & $1 / 9$ & 1 & 0.045 \\
\hline & & & & CR $=\mathbf{0 . 0 9 2}$ \\
\hline
\end{tabular}

In the case in point, each of the four criteria is subdivided into only two subcriteria. Therefore, the priorities between the subcriteria with regard to each criterion are more easily obtained directly, without the need of comparison matrixes. Table 13 shows the judgments given by the group of executives involved with the assessment.

Table 13

Relative priority between subcriteria with regard to each criterion.

\begin{tabular}{|l|l|c|}
\hline Criteria & Subcriteria & Relative Priority \\
\hline \multirow{2}{*}{ Commissioning } & Freight & 0.6 \\
& Office & 0.4 \\
\hline \multirow{2}{*}{ Client } & Potential commitment & 0.3 \\
& Loyalty & 0.7 \\
\hline \multirow{2}{*}{ Destination } & Route & 0.6 \\
& Transit time & 0.4 \\
\hline \multirow{2}{*}{ Load } & Weight & 0.4 \\
& Volume & 0.6 \\
\hline
\end{tabular}

Finally, the results of the comparison between the criteria with regard to the goal of the analysis are shown in Table 14.

Table 14

Comparison of criteria with respect to the goal.

\begin{tabular}{|l|c|c|c|c|c|}
\hline & Commissioning & Client & Destination & Load & Relative Priority \\
\hline Commissioning & 1 & 7 & 5 & 4 & 0.594 \\
\hline Client & $1 / 7$ & 1 & $1 / 5$ & $1 / 5$ & 0.049 \\
\hline Destination & $1 / 5$ & 5 & 1 & $1 / 2$ & 0.145 \\
\hline Load & $1 / 4$ & 5 & 2 & 1 & 0.212 \\
\hline & & & & & CR $=\mathbf{0 . 0 8 1}$ \\
\hline
\end{tabular}

\subsection{Verification of the consistency}

In the previous section, the final consensual results were presented. Actually, several meetings were held in order to assess the internal consistency of the comparisons made. Initially the comparison matrixes of the alternatives with regard to the subcriteria freight, potential, transit time and volume presented unacceptable inconsistencies (CR over 0.1). Faced with these, the group carried out a more in-depth analysis, revising their assessments, and finally obtained a consistent model.

\subsection{Prioritization of the alternatives}

Table 15 shows the final result of the prioritization model. 
Table 15

Composite priorities of the alternatives.

\begin{tabular}{|c|c|c|c|c|c|}
\hline & $\begin{array}{c}\text { Commissioning } \\
\mathbf{( 0 . 5 9 4 )}\end{array}$ & $\begin{array}{c}\text { Client } \\
\mathbf{( 0 . 0 4 9 )}\end{array}$ & $\begin{array}{c}\text { Destination } \\
\mathbf{( 0 . 1 4 5 )}\end{array}$ & $\begin{array}{c}\text { Load } \\
\mathbf{( 0 . 2 1 2 )}\end{array}$ & Composite \\
\hline A & 0.266 & 0.626 & 0.155 & 0.398 & $\mathbf{0 . 2 9 5}$ \\
\hline B & 0.368 & 0.044 & 0.088 & 0.047 & $\mathbf{0 . 2 4 4}$ \\
\hline C & 0.156 & 0.250 & 0.531 & 0.416 & $\mathbf{0 . 2 7 0}$ \\
\hline D & 0.210 & 0.080 & 0.226 & 0.139 & $\mathbf{0 . 1 9 1}$ \\
\hline CR & $\mathbf{0 . 0 2 1}$ & $\mathbf{0 . 0 7 6}$ & $\mathbf{0 . 0 9 5}$ & $\mathbf{0 . 0 9 2}$ & $\mathbf{0 . 0 4 9}$ \\
\hline
\end{tabular}

\section{Analysis}

The ranking of the alternatives obtained through the application of the AHP technique, reflecting the choice of the sales team, shows that the first priority should be to attend client $\mathrm{A}$, followed by clients $\mathrm{C}, \mathrm{B}$ and $\mathrm{D}$.

A comparison of the relative weights of the general criteria clearly demonstrates that the company is focused on serving the clients with the highest level of commissioning (0.594 against $0.212 ; 0.145$, and 0.149 ). This positioning is easily explained by the fact that the company gets paid through commission on the freight.

In an attempt to make a comparison with the system usually employed by the agency, the participants were encouraged to reflect on the decision in question. When initially confronted with the four alternatives, before using the AHP technique, most of the participants in the decision making process chose to attend client $\mathrm{A}$, with only one person in the group choosing to attend client $\mathrm{C}$. In the light of the results achieved with the AHP technique, this is not surprising, as almost $60 \%$ of the total weight among the criteria fall on the commissioning criterion (subdivided into freight and confirmation) and the alternatives $\mathrm{A}$ and $\mathrm{C}$ offer the most advantages from this point of view.

Nevertheless, the participants were unanimous in stating that the use of the technique highlighted the differences of opinion in judging the alternatives helping them to better understand the situation, which facilitated circumvent conflicts thus achieving the desired consensus. The executives reported major difficulties concerning the comparison between alternatives. While the pairwise comparisons of the criteria did not present significant problems of inconsistency for the executives, the comparisons between the alternatives presented initial inconsistencies. These inconsistencies were removed during the bargaining process and the settling of participants' opinions.

The technique proved to be very useful in grasping a solution to the problem, and its capacity to treat quantitative and qualitative elements interactively was particularly outstanding. At each step through the process, trying to bypass inconsistencies between judgments, the participants enhanced their individual understanding of the difficult decision they were confronted with. The decision is difficult since the situation of scarcity of space on the vessels results that some clients' shipments might not be booked, causing dissatisfaction. Although difficult the problem was facilitated by the technique.

\section{Final remarks}

The model proposed in this paper provides a new perspective to the process of decision making in the organization in which this research was carried out. By aiding the decision on operational activities (selection of clients and booking confirmations) based on strategic guidelines of the organization (agency), it broadened the managers' view. The technique, through its process of analysis, comforts the decision maker in the sense that the decision is being taken with the consensus both of the sales team and the top management. 
The application of the AHP technique in this study, including the participation of the sales team and the adoption of multicriteria richly distinguishing the alternatives, allows the documentation of the decision making process of prioritizing clients. Accordingly, the recommendation of the most suitable alternative is made in formal grounds since the application of the model is fully validated. The opinions of all different agents involved are consolidated in the analysis through the weights of the several objects compared.

With the help of the mathematical technique, it was possible to jointly assess the criteria and subcriteria and prioritize the alternatives, consistently. Without it, one would risk inconsistencies in judgment, since these would be made intuitively and separately. Obviously, the technique served as a support for the managers, does not substituting them. By offering a prioritized list of alternatives, the technique allows the decision to be taken more secure since the result was obtained through various levels of analysis and consensually by a group of specialists.

As a suggestion for future research, the proposed model could be extended to other situations requiring important decisions within the company. For instance, the technique could be applied in situations of overbooking, when the shipping agency needs to decide to cut cargoes from a determined vessel.

\section{REFERENCES}

Ackoff, R.L., \& Sasieni, M. (1968). Fundamentals of operations research. New York: John Wiley \& Sons.

ANTAQ (2009). Anuário Estatístico Portuário (AEP) - Brasília: Governo Federal - Ministério dos Transportes, 2007. Retrieved April 23, 2009, from http:/www.antaq.gov.br/Portal/Anuarios/ Portuario2007/Index.htm.

CAPES (2009). Banco de Teses. Retrieved May 22, 2004, from http://capes.gov.br/servicos/banco-deteses.

Golden, B.L., Wasil, E.A., \& Harker, P.T. (1989). The analytic hierarchy process: Applications and studies. Berlin: Springer-Verlog.

HO, W. (2008). Integrated analytic hierarchy process and its applications - A literature review. European Journal of Operational Research, 186(1), 211-228.

Saaty, T.L. (1980). The analytic hierarchy process: Planning, priority setting, resource allocation. New York: McGraw-Hill.

SCIELO (2009). SCIELO Brasil. Retrieved May 22, 2009, from http://www.scielo.br/cgi-bin/ wxis.exe/iah/.

Vaidya, O.S., \& Kumar, S. (2006). Analytic hierarchy process: An overview of applications. European Journal of Operational Research, 169(1), 1-29.

WTO (2009). World Trade Organization. Retrieved May 25, 2009, from http://stat.wto.org/ CountryProfile/WSDBCountryPFView.aspx? Language=E\&Country=BR. 